\title{
Social inequality and depressive disorders in Bahia, Brazil: interactions of gender, ethnicity, and social class
}

\author{
Naomar Almeida-Filho ${ }^{\mathrm{a}, *}$, Ines Lessa ${ }^{\mathrm{b}}$, Lucélia Magalhães ${ }^{\mathrm{b}}$, Maria Jenny Araújo ${ }^{\mathrm{b}}$, \\ Estela Aquino ${ }^{b}$, Sherman A. James ${ }^{\text {c }}$, Ichiro Kawachi ${ }^{\mathrm{d}}$ \\ ${ }^{a}$ Instituto de Saúde Coletiva at the Federal University of Bahia (Campus Canela, Salvador, Bahia 40210-070 Brazil) \\ and Center for Society and Health, Harvard School of Public Health, Brazil \\ ${ }^{\mathrm{b}}$ Instituto de Saúde Coletiva at the Federal University of Bahia, Bahia, Brazil \\ ${ }^{\mathrm{c}}$ Department of Epidemiology and Center for Research on Ethnicity, University of Michigan School of Public Health, USA \\ ${ }^{\mathrm{d}}$ Center for Society and Health and Department of Health and Social Behavior, Harvard School of Public Health, USA
}

\begin{abstract}
We conducted a study of the association between gender, race/ethnicity, and social class and prevalence of depressive disorders in an urban sample $(N=2302)$ in Bahia, Brazil. Individual mental health status was assessed by the PSAD/ QMPA scale. Family SES and head of household's schooling and occupation were taken as components for a 4-level social class scale. Race/ethnicity (white, moreno, mulatto, black) was assessed with a combination of self-designation and a system of racial classification. The overall 12-month prevalence of depressive symptoms was $12 \%$, with a female:male ratio of 2:1. Divorced/widowed persons showed the highest prevalence and single the lowest. There was a negative correlation with education: the ratio college educated:illiterate was 4:1. This gradient was stronger for women than men. There was no F:M difference in depression among Whites, upper-middle classes, college-educated, or illiterate. Prevalence ratios for single, widowed and Blacks were well above the overall pattern. Regarding race/ ethnicity, higher prevalences of depression were concentrated in the Moreno and Mulatto subgroups. There was a consistent social class and gender interaction, along all race/ethnicity strata. Three-way interaction analyses found strong gender effect for poor and working-class groups, for all race/ethnicity strata but Whites. Black poor yielded the strongest gender effect of all (up to nine-fold). We conclude that even in a highly unequal context such as Bahia, Blacks, Mulattos and women were protected from depression by placement into the local dominant classes; and that the social meaning of ethnic-gender-generation diversity varies with being unemployed or underemployed, poor or miserable, urban or rural, migrant or non-migrant.
\end{abstract}

(C) 2004 Elsevier Ltd. All rights reserved.

Keywords: Depression; Social class; Gender; Ethnicity; Inequity; Brazil

\section{Introduction}

In the USA, the Epidemiological Catchment Area (ECA) study and the National Comorbidity Study (NCS) confirmed that depression is the most common psychiatric disorder, with a lifetime prevalence of up to $17 \%$, either in isolation or comorbid with anxiety and

\footnotetext{
*Corresponding author. Tel.: + 5571-245-0151; fax: + 5571237-5856.

E-mail address: naomar@ufba.br (N. Almeida-Filho).
}

substance abuse disorders (Robins \& Regier, 1991; Kessler et al., 1994). Similar results have been found for European countries in the Outcome of Depression International Network (ODIN) study (Ayuso-Mateos et al., 2001). A WHO survey conducted in 14 countries found depression to be the most frequent psychological problem in primary care, with an average lifetime prevalence of $20 \%$ (Maier et al., 1999).

Consistently, research findings suggest that people from lower social strata are more likely to suffer from mental health problems, including depression, than 
those in the upper and middle classes (Link, Lennon, \& Dohrenwend, 1993; Wohlfarth, 1997). Two sets of explanations have been advanced to account for the observed socioeconomic disparities. The social selection explanation gives causal priority to the onset of mental illness as a factor preceding the disadvantaged placement of individuals into social scales. The social causation approach argues that poverty and low social class give rise to poor mental health. Ritsher and Colleagues (2001) suggest that social selection may be more salient for schizophrenia in men, while social causation may be more important for unipolar depression in women (Ritsher et al., 2001; Warner, Johnson, \& Dohrenwend, 2001). More recently, there has been increasing interest in examining social inequalities in mental illness (Muntaner, Eaton, \& Diala, 2000). Inequality in society can be defined along a variety of dimensions, including gender, race/ethnicity and social class.

With respect to gender, there has been continuing interest in explaining the ubiquitous finding that depression and related disorders are more common among women (Bebbington, 1996; Piccinelli \& Wilkinson, 2000; Weissman \& Klerman, 1977). Sociopsychological explanations for this gender pattern have focused on the greater exposure of women to psychosocial adversity, on women's reporting of symptoms at earlier stages of disorder than men, as well as differences in responses to stress, which in turn reflect gender differences in role expectations (Bebbington, 1998). Another related approach to this issue emphasizes gender differences in labor market demands and participation in the labor force (Lennon, 1995).

Although attempts to define the constructs of race and ethnicity still provoke considerable debate, there is emerging consensus that these constructs represent social as much as biological categories, predicated upon human relations characterized by oppression and subordination (Krieger, 2000). Associations of gender and race/ethnicity with higher rates of morbidity may be also hypothesized to be the result of discrimination through sexism and racism (Krieger, Rowley, Herman, Avery, \& Phillips, 1993; Lillie-Blanton \& Laveist, 1996). In mental health, despite many attempts to privilege the biological aspects of race/ethnicity (Lin, 2001), the empirical relationship of ethnic and racial status with the occurrence of psychiatric disorders has not been established consistently. For example, the association of race/ethnicity with mental disorders in the NCS and the ECA studies was either weak or non-existent (Kessler et al., 1994; Robins \& Regier, 1991). There is therefore much room for research exploring the socioeconomic mediators of race/ethnicity.

Indeed, the interactions between SES, gender and race/ethnicity as determinants of depressive disorders represent complex processes that, by definition, are also context and culture-dependent. There have been reported analyses that partially account for social status and ethnic group interaction (Kessler et al., 1994), or gender and racial/ethnic contrasts (Turner \& Gil, 2002; Williams, Takeuchi, \& Adair, 1992). However, to disentangle the complex interactions between these variables, we need studies in specific research settings that allow the joint and isolated effects of each variable to be ascertained. By virtue of having populations with varying degrees of racial admixture and ethnic and social integration (Kraay \& Levine, 1998), Brazil provides an optimal context for research on this topic. Indeed, in many regions of the country there is much social inequality and variation of education and income across gradients of race/ethnicity (Reichmann, 1999). In addition, one can find social and historical similarities between the racial/ethnic contexts of Brazil and the US that are strong enough to justify cross-national comparisons (Nobles, 2000).

In Brazil, higher prevalence rates of mental disorders including depression were found among poor, illiterate and urban migrants (Almeida-Filho, 1982; AlmeidaFilho and Bastos, 1982; Coutinho, 1976; Santana, 1982). Such findings were interpreted mainly with a culturalist approach but subsequent analyses of social determinants implicated unemployment and social exclusion as the primary mechanisms underlying the explanation of inequalities in mental health (Almeida-Filho, 1987). These investigations employed categories of psychopathology (e.g. neurosis or stress) too broad to allow the identification of social correlates of specific conditions, such as depression, and generated findings regarding highly specific samples, thus precluding generalizations to the general population. A second wave of psychiatric morbidity surveys (Almeida-Filho et al., 1997; Andrade, Walters, Gentil, \& Laurenti, 2002; Lima, Soares, \& Mari, 1998; Mari, et al., 1993; Vorcaro, Lima-Costa, Barreto, \& Uchoa, 2001), with comparable design and classification systems, showed distribution patterns and prevalence rates specific for diagnostic categories similar to those found in the original ECA studies. However, in these surveys, gender was treated more as a confounder to be controlled for, while socioeconomic variables were analyzed as risk factors for minor psychiatric disorders. Their findings point to the need to take gender and ethnicity into account - in addition to social determinants such as social class and labor relations-as fundamental dimensions for mental health. Despite Brazil's history of racial miscegenation and race relations, no specific studies have been reported on racial/ ethnic inequalities, or potential interactions among ethnicity, gender and social variables, as related to epidemiological patterns of depression.

This paper explores the inequalities in depressive disorder along the dimensions of gender, ethnicity and social class based on a representative urban sample of 
Salvador, in the state of Bahia, Brazil. The data analyzed was produced by a multistage survey planned to serve as a baseline for a follow-up study on the ethnoepidemiology of psychosocial health, cardiovascular disorders and related conditions.

\section{Methods}

\section{Research site}

The city of Salvador (population: 2,556,013-2000 Census) is the capital of the Northeastern State of Bahia, the oldest Brazilian settlement that was the government center of the colony until 1750 (Risério, 2000). Between the 16th and 19th centuries, it was a major port of entry for the slave trade from Africa (Kraay \& Levine, 1998). This has deeply influenced the state's cultural and demographic profile - over $70 \%$ of the population is of African origin, mainly from gege (Yoruba) nations. These distinctive historical and cultural features are manifested in the arts, language, cuisine, and particularly in the elaborated rituals of the Afro-Brazilian religions (Candomblé and Umbanda), with Christian, African, and Amerindian syncretism (Bastide, 1978; Rego, 1980). Despite the use of nago (the Yoruba language) in religious rituals and in music and literature, Portuguese is spoken by all groups of the Bahian population.

Currently, Bahia (population: thirteen million-2000 Census) is the largest and most populated state of Northeast Brazil, which is the most impoverished region of the country. Recently, Bahia received massive capital investments for industrial development and government sponsored policies helped to transform Salvador (and the surrounding beach sites) into one of the most important tourist centers in the country (Queiroz, 1995). These economic developments and the rapid urbanization of Brazil have stimulated massive migration to urban centers and created an imbalance between the urban labor force and the number of available jobs (Borges \& Filgueiras, 1995). This has resulted in under-employment and unemployment, with the deterioration of living conditions for the majority of the city's population, leading to the establishment of poor neighborhoods, called favelas (shantytowns) or invasões (squatter settlements), along the perimeter of the city (Souza \& Faria, 1980). However, this same process of economic development has determined the formation of a powerful (though not very large, given the extreme income concentration in Brazil) urban ruling class, residing in comfortable and well-guarded apartment buildings, condominiums, and mansions. For the local residents, these areas embody contrasting identities. Whereas beachside neighborhoods represent the new and prosperous side of the city, favelas and invasões are marked by the stigma of poverty, marginalization and violence.

In contrast to the presence of self-ascribed white groups in the few affluent sections of the city, there is a strong concentration of people with African ancestry in low-income neighborhoods in Salvador. Census data revealed that more than $40 \%$ of the population can be classified below the poverty line and that $60 \%$ of city residents live in underprivileged areas. Population genetic studies (Azevedo, Fortuna, Silva, \& Silva, 1982; Lima \& Azevedo, 1991) have shown that the majority of the Bahian population $(65 \%)$ is racially mixed, with a small proportion $(20 \%)$ of Blacks and an even smaller proportion (15\%) of Whites. Therefore, the self-designated status of "white" in the upper/middle classes must be considered in terms specific to the Brazilian ethnic and social context (Reichmann, 1999).

\section{Sampling strategy}

We used a three-stage random sample by conglomerates. In the first stage, for the definition of survey areas, contiguous census tracts sharing the same sociodemographic characteristics were merged in order to ensure a total of between 100 and 200 families in each. This produced 108 areas, which were classified into three classes according to family SES level: predominantly high, mixed and predominantly low. These areas included 16,592 households and approximately 83,000 inhabitants. 37 areas were randomly selected, proportional to the number of areas in each SES. In the second stage, a random systematic sampling of households was conducted for each survey area using a sampling interval of 10 homes. A total of 1540 homes were visited and 1458 were considered eligible for participating in the survey. All members of selected families were invited to take part in a general register of homes and participants, along with basic socio-demographic data (age, sex, and position in the household). At this stage, the refusal rate was $9.1 \%$. In the third sampling stage, for each family that agreed to participate in the study, two adults ( $>20 \mathrm{yr}$ of age), one male and one female (excluding pregnant women), were randomly selected for participating in the study. The final sample consisted of 2302 adults from 1258 families, who resided in 63 census tracts. The sample included more females (1250) than males (1052), reflecting the prevalence of families headed by women, as well as a higher non-response rate among men $(5.9 \%)$ compared to women $(1.8 \%)$.

\section{Data collection procedures}

The field research team was composed of one registered nurse, two nutritionists and ten trained lay interviewers, all women, recruited from the neighborhoods included in the research. They received a 72-h 
training program, through techniques of role-playing, and passed several reliability tests (e.g. inter-rater reliability) throughout the fieldwork. They were also trained in a field pilot-study by practicing questionnaire administration to families not included in the sample. The lay interviewers located the households and completed a family information sheet for the collection of socio-demographic information on all residents identified, and scheduled visits for interviews and individual exams. Each interviewer was in charge of approximately 100 families. They were instructed to do the first visit during meal times or on weekends or evenings, and to visit up to three times before coding the unit as missing. The heads of household as well as the individuals selected for individual interviewing were asked to read and sign a consent form prior to participating in the study.

Data on use of health services, and nutritional, biomedical and psychometric assessments were collected individually by the team of health professionals using instruments field-tested in the pilot-study. The basic instrument of data collection was a modular questionnaire containing socio-demographic individual data: age, gender, ethnicity; social data: family socioeconomic status (SES), schooling, migration (age at time of migration, itinerary), occupational history; cardiovascular risk factors; biological data: consanguinity, age of menarche and menopause, obesity, diabetes and cardiovascular family history. Field supervisors (L.M., M.J.A.) monitored the data collection closely, re-visiting participating families at random for quality control purposes. The Ethics Research Council of UFBA Faculty of Medicine approved the research protocol.

\section{Study variables}

The social inequality variables most commonly used in public health research are SES and social class (Krieger, Williams, \& Moss, 1997) including education, occupation, income, or levels of individual or familial consumption. To assess family consumption, an inventory of household appliances and consumer goods (refrigerator, TV set, telephone, videocassette player, microwave oven, car possession) was completed and checked by direct observation. Levels ranged from A-highest to E-lowest, according to the standard of ABPEME-Brazilian Association of Market Research. The household SES and the head of household's occupation and schooling were taken as components for a four-level social class scale (upper, middle, working-class, poor). This variable was treated in the analysis as a family attribute. Upper and middle class families were defined, respectively, by high or medium level in the consumption scale, by university or high school education and by the social position of the head of household; i.e. whether $\mathrm{s} / \mathrm{he}$ was an employer or an employee in a permanent formally contracted job. Working-class families were those placed in the lower levels of the consumption scale whose heads of household were self-employed or had a stable work and elementary school education. Poor families were those in the lowest levels of the consumption scale and whose heads of household had no stable work and were not self-employed.

In order to assess race/ethnicity, respondents were invited to classify themselves on a five-level skin-color classification developed for population genetic studies specific to Bahia (Azevedo et al., 1982; Lima \& Azevedo, 1991): white, light-mulatto, medium-mulatto, darkmulatto, black. However, 634 participants (almost $30 \%$ ) refused to classify themselves according to this scheme, preferring to use other self-designations. The interviewers were instructed to encourage such alternative classifications by using an open-ended category, in order to maintain rapport with respondents. Information thus obtained was later recoded to fit one of the five aforementioned categories. By the end, we had collected 18 different racial/ethnic self-designations, with the most frequent being: claro, moreno, sarará, cabo-verde, marron, pardo, escuro, preto. Moreno (equivalent to light-brown skinned person with facial features neither distinctly African nor European) was the term most frequently used. We chose to use this term to classify light-mulattos as well. Escuros and pretos were classified as Black while the claras (mostly women) were classified as Whites. All others were classified as Mulattos. It should be noted that in Brazilian Portuguese, unlike in American English, there is neither a semantic distinction nor a pejorative sense associated with the terms negro and preto (both can be translated as black). A small number of respondents (60 subjects) indicated Oriental, Amerindian, Jewish or foreign-born ethnic origin. Since they do not represent a separate racial/ethnic group in the Bahian context, they were excluded from analyses pertaining to race/ethnicity.

The validity and reliability of data on race or ethnicity, and their related conceptual and methodological problems, have only recently begun to be discussed in health research (BMJ, 1996; Bhopal, 1997). A recent study by Fuchs and Colleagues (2002), in Southern Brazil, found agreement beyond chance between selfassigned race/ethnic categories and interviewer observed skin color $(\kappa=0.75 ; 95 \%$ CI: 0.71-0.79). Considering the racial/ethnic differences in Brazil, Fuchs et al. added that the self-designation of race/ethnicity includes terms that belong to regional glossaries, "which makes comparisons difficult between national and international studies" (Fuchs et al., 2002). For this reason, we felt the most reasonable strategy to take in measuring race/ethnicity in Bahia was a combination of self-designation and a well-established system of racial classification. 
Individual mental health status was assessed by the administration of the Psychosomatic-Anxiety-Depression (PSAD) subscale of the Questionário de Morbidade Psiquiátrica de Adultos (QMPA). Deriving from Goldberg's GHQ, the QMPA consists of 44 items. The QMPA was developed by Santana (1982) for case identification in psychiatric morbidity surveys and tested for validity and reliability in different research settings in Brazil. Validation tests have demonstrated adequate sensitivity (89-93\%), and specificity (72-98\%), and low misclassification rates $(6-12 \%)$ for the instrument. The reliability study of the supporting diagnoses revealed a $\kappa$ of +0.88 (Santana, 1982). It has since been largely employed for epidemiologic studies of mental disorders in Brazil. Andreoli et al. (1994), after analyzing the psychometric properties of the QMPA using principal component analysis, extracted 10 components, and three of these - anxiety, depression and alcoholism - came out consistently in different research sites. These dimensions clustered around the same symptoms, with 12 items found to be the most reliable and stable for depression and anxiety, forming the basis of the PSAD/QMPA (Andreoli et al., 1994).

The form used in this study consisted of direct questions in the local urban idioms, covering the following symptoms: aggressiveness and irritability, "nerves" or vague pain, sleep problems, headaches, ear-noise or "head-buzzing", palpitations and heartburn, trembling or cold hands, fatigue and weakness in the legs, excessive concern with diseases, sadness and easy crying, discouragement or negativism, and social withdrawal. The final five items were included in the depression component developed by Andreoli et al. (1994). All symptoms referred to the past 12-month period. Answers were coded on a 4-point Likert scale (0-never, 1-rarely, 2-sometimes, 3-frequently). Cases of depression were defined as those subjects who scored $>22$ in the PSAD/QMPA and who had a score on the depression subscale above the cut-off point of 12 . Therefore, for someone to be diagnosed as depressed in the past year, he/she needed to have reported at least three symptoms specific for depression plus scoring in the upper quintile of the PSAD/QMPA scale. This approach to case definition is comparable to those used in several recent surveys on psychosocial health, such as the British National Psychiatric Morbidity Survey (Jenkins et al., 1997), the Alameda County Study (Yen \& Kaplan, 1999), the ODIN Study (Ayuso-Mateos et al., 2001), the Whitehall II Study (Griffin, Fuhrer, Stansfeld, \& Marmot, 2002).

\section{Data analysis}

Prevalence rates and measures of association were estimated for each category of the independent variables. The identification of patterned inequalities allowed for the establishment of specific cut-points for each of the social and racial/ethnic variables. Considering the sampling design, separate analyses were conducted for each of the gender categories through the calculation of Female:Male (F:M) prevalence ratios. No correction of standard error for rate estimations due to the cluster sampling design was performed. Odds-ratios were calculated for categories of covariables and, whenever indicated, with adjustments for the control of confounding through logistic regression. Adjusted odds-ratios were estimated by modeling only terms that reached statistical significance of $\alpha=0.05$ in each specific group except for age, which was forced into all models. Tests of interaction were conducted through the use of cross-product terms. For data processing and statistical analysis, we used the software Minitab, version 1.3. Adjusted measures were calculated for each category of the effect modification variables, using Statcalc EpiInfo for the estimation of summary measures of association. For the assessment of statistical significance, we used Mantel-Haenszel weighted $\chi^{2}$ and Taylor-series confidence intervals (and, whenever indicated due to small size strata, Fisher's exact tests and Greenland-Robinson confidence limits).

\section{Results}

Table 1 presents the main demographic characteristics of the sample. Despite efforts to obtain a sample balanced for gender, women were slightly more numerous than men (11.4\% excess), particularly in the younger and older age groups. A majority $(65 \%)$ of the sample was married. One-fourth was single while widowed and separated or divorced together accounted for around $10 \%$. More women were widowed or divorced than men $(16 \%$ compared to $3.5 \%)$. Half of the sample was migrants, mostly coming from other municipalities in Bahia.

Table 1 also shows the social and racial/ethnic composition of the sample. Education and SES levels reveal the low social conditions of that population as a whole. The majority $(58 \%)$ of the sample attained only elementary education. Illiteracy was $6 \%$. Only $5 \%$ had college education. Women were slightly less educated, with $8 \%$ illiteracy compared to $3.5 \%$ for men. Less than $3 \%$ of the sample was classified as upper class and $13 \%$ as middle class. Almost 30\% were working class, while the majority $(55 \%)$ was classified as poor. Since this was a family based variable, there were no differences by gender. Regarding the racial/ethnic composition of the sample, the majority (46\%) selfidentified as Morenos, followed by Blacks (21\%) and Mulattos $(16 \%)$. Whites were only $15 \%$ of the sample. Less than $3 \%$ of those interviewed declared a different ethnic origin. 
Table 1

Socio-demographic profile of the sample. Salvador, Brazil, 2001

\begin{tabular}{|c|c|c|c|c|c|c|}
\hline \multirow[t]{2}{*}{ Variables } & \multicolumn{2}{|c|}{ Men } & \multicolumn{2}{|c|}{ Women } & \multicolumn{2}{|c|}{ Total } \\
\hline & $N$ & $(\%)$ & $N$ & $(\%)$ & $N$ & $(\%)$ \\
\hline \multicolumn{7}{|l|}{ Age group } \\
\hline$>25$ & 163 & $(15.5)$ & 144 & $(11.5)$ & 307 & $(13.3)$ \\
\hline $25-34$ & 256 & (24.3) & 304 & $(24.3)$ & 560 & $(24.3)$ \\
\hline $35-44$ & 282 & $(26.8)$ & 324 & $(25.9)$ & 606 & $(26.3)$ \\
\hline $45-54$ & 173 & (16.4) & 222 & (17.8) & ) 395 & $(17.2)$ \\
\hline $55+$ & 178 & (16.9) & 256 & $(20.5)$ & 434 & $(18.8)$ \\
\hline \multicolumn{7}{|l|}{ Marital status } \\
\hline Single & 291 & (27.9) & 273 & $(21.9)$ & 564 & $(24.6)$ \\
\hline Married & 715 & $(68.5)$ & 768 & $(61.7)$ & 1483 & $(64.8)$ \\
\hline Widowed & 16 & $(1.5)$ & 116 & $(9.3)$ & 132 & $(5.8)$ \\
\hline Separated/divorced & 21 & $(2.0)$ & 88 & (7.1) & 109 & $(4.8)$ \\
\hline \multicolumn{7}{|l|}{ Migration } \\
\hline Non-migrant & 538 & $(51.3)$ & 606 & $(48.5)$ & 1144 & $(49.8)$ \\
\hline Migrant & 511 & $(48.7)$ & 643 & $(51.5)$ & 1154 & $(50.2)$ \\
\hline \multicolumn{7}{|l|}{ Education } \\
\hline College & 49 & $(4.7)$ & 62 & $(5.0)$ & 111 & $(4.8)$ \\
\hline High school & 317 & $(30.4)$ & 392 & $(31.5)$ & 709 & $(31.0)$ \\
\hline Elementary school & 642 & (61.5) & 693 & $(55.8)$ & 1335 & $(58.4)$ \\
\hline Illiterate/read & 36 & $(3.5)$ & 96 & (7.7) & 132 & $(5.8)$ \\
\hline
\end{tabular}

Educational divide

$\begin{array}{lllllll}\text { [College-high school] } & 366 & (35.0) & 454 & (36.5) & 820 & (35.8)\end{array}$

$\begin{array}{llllllll}\text { [Elementary-illiterate] } & 678 & (65.0) & 789 & \text { (63.5) } & 1467 & (64.2)\end{array}$

Social class

Upper

Middle

Working class

Poor

$\begin{array}{rrrrrr}24 & (2.4) & 28 & (2.3) & 52 & (2.4) \\ 122 & (12.1) & 162 & (13.5) & 284 & (12.8) \\ 303 & (30.0) & 350 & (29.1) & 653 & (29.5) \\ 561 & (55.5) & 661 & (55.0) & 1222 & (55.3)\end{array}$

Social divide

[Upper-middle] $\quad 146 \quad(14.5) \quad 190 \quad(15.8) \quad 336 \quad(15.2)$

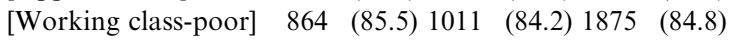

Ethnic group

White

Moreno

Mulatto

Black

Other

$\begin{array}{rrrrrr}150 & (14.4) & 190 & (15.3) & 340 & (14.9) \\ 487 & (46.7) & 560 & (45.2) & 1047 & (45.9) \\ 175 & (16.8) & 189 & (15.2) & 364 & (15.9) \\ 211 & (20.2) & 261 & (21.1) & 472 & (20.7) \\ 20 & (1.9) & 40 & (3.2) & 60 & (2.6)\end{array}$

Ethnic divide

[White]

[Non-white]

$\begin{array}{llllll}150 & (14.4) & 190 & (15.3) & 340 & (14.9)\end{array}$

$893 \quad$ (85.6) $1050 \quad(84.7) 1943 \quad(85.1)$

Total

$1052(100.0) 1250(100.0) 2303(100.0)$

According to Table 2, the overall prevalence of depressive symptoms was $12.2 \%$. Rates of depression increased from $6.8 \%$ to $17 \%$ across age groups from young adulthood through 54 years old, but dipped to
$10.6 \%$ among those 55 and older. The higher rates found between 35 and 54 years of age were statistically significant $(\mathrm{ORs}>2.0)$ even after controlling for gender, marital status and education. Depression was more prevalent among females than among males (16.6\% compared to $6.9 \%$ ) with an adjusted odds-ratio of 2.65 . Divorced and widowed persons showed the highest prevalence (19.1\% and $16.4 \%$, respectively), compared to married $(12.7 \%)$ and single $(8.3 \%)$ persons. Using single individuals as the referent group, controlling for potential confounders still yielded odds ratios statistically significant at 0.05 levels for married $(A O R=1.55)$ and for divorced and widowed combined (AOR $=1.69)$. Migration was not associated with the prevalence of depression.

Also in Table 2, a marked gradient of depression prevalence by educational level was highly significant $\left(\chi_{\text {trend }}^{2}=18.16 ; p<0.0005\right)$. The prevalence among college educated was $5.4 \%$, or 2.8 times lower than those with elementary school education, and 3.7 times lower than illiterate subgroups. After adjustment for confounders, these ratios were still significant. Also, contrasting the prevalence of college-high school and elementary-illiterate yielded a highly significant ratio $(\mathrm{AOR}=1.53)$. The middle-class group showed the lowest prevalence $(6.3 \%)$ while the working-class group had the highest $(13.5 \%)$. Despite the common assumption that education is a good proxy for SES, a linear trend was not observed for the association between depression and educational attainment. However, after grouping the upper-middle and poor-working classes, this social class divide was associated with depressive disorders even after controlling for confounders (AOR =2.17). Finally, the White racial/ethnic group showed the lowest prevalence $(9.4 \%)$, followed by Blacks $(11.2 \%)$. The highest prevalence of depression was found among Mulattos (15.7\%). After adjusting for the other variables, only the Mulatto subgroup showed a statistically significant association with depression $(A O R=1.78)$. The White vs. Non-White divide was marginally significant $(\mathrm{AOR}=1.40)$.

Table 3 analyzes the age-adjusted prevalence of depression according to gender, stratified by sociodemographic variables. The female vs. male (F:M) standardized prevalence ratios were highly significant for all strata of marital status and migration, varying from 1.55 (migrants) to 9.06 (widowed and divorced, taken together). Women with elementary and high school education were at 2.64 and 2.14 times the risk of depression, respectively, compared with equivalently educated men. For the social class strata, only workingclass and poor showed highly significant $\mathrm{F}: \mathrm{M}$ ratios (combined, 2.63; MH $\chi^{2}=54.57 ; p<0.0005$ ). The analysis regarding ethnicity revealed higher prevalence among women for all racial/ethnic groups except for Whites $\left(\mathrm{PR}=1.51 ; \chi^{2}=1.36\right)$. 
Table 2

Prevalence (per cent) of depressive disorders according to selected independent variables. Salvador, Brazil, 2001

\begin{tabular}{|c|c|c|c|c|c|c|}
\hline Variables & Prevalence per 100 & Crude OR & $(95 \% \mathrm{CI})$ & AOR & $(95 \% \mathrm{CI})$ & Models \\
\hline \multicolumn{7}{|l|}{ Age group } \\
\hline$<25$ & 6.8 & 1.00 & - & 1.00 & - & \multirow{5}{*}{$\begin{array}{l}\text { GENDER, } \\
\text { MST, EDUCDIV }\end{array}$} \\
\hline $25-34$ & 10.4 & 1.57 & $(0.94 ; 2.65)$ & 1.43 & $(0.83 ; 2.48)$ & \\
\hline $35-44$ & 14.5 & 2.31 & $(1.41 ; 3.80)$ & 2.08 & $(1.21 ; 3.56)$ & \\
\hline $45-54$ & 17.0 & 2.78 & $(1.66 ; 4.66)$ & 2.43 & $(1.39 ; 4.26)$ & \\
\hline$>55$ & 10.6 & 1.61 & $(0.94 ; 2.77)$ & 1.17 & $(0.63 ; 2.15)$ & \\
\hline \multicolumn{7}{|l|}{ Gender } \\
\hline Men & 6.9 & 1.00 & - & 1.00 & - & \multirow{2}{*}{$\begin{array}{l}\text { MST, } \\
\text { SESDIV }\end{array}$} \\
\hline Women & 16.6 & 2.66 & $(2.01,3.52)^{\mathrm{c}}$ & 2.65 & $(1.99 ; 3.56)^{\mathrm{c}}$ & \\
\hline \multicolumn{7}{|l|}{ Marital status } \\
\hline Single & 8.3 & 1.00 & - & 1.00 & - & \multirow{3}{*}{$\begin{array}{l}\text { AGE, GENDER, } \\
\text { SESDIV }\end{array}$} \\
\hline Married & 12.7 & 1.61 & $(1.15,2.25)^{\mathrm{b}}$ & 1.55 & $(1.10 ; 2.19)^{\mathrm{a}}$ & \\
\hline Widowed/divorced & 17.4 & 2.32 & $(1.48,3.63)^{\mathrm{c}}$ & 1.69 & $(1.06 ; 2.69)^{\mathrm{a}}$ & \\
\hline \multicolumn{7}{|l|}{ Migration } \\
\hline Non-migrant & 11.5 & 1.00 & - & 1.00 & - & \multirow{2}{*}{$\begin{array}{l}\text { GENDER, } \\
\text { MST, EDUCDIV }\end{array}$} \\
\hline Migrant & 12.9 & 1.10 & $(0.85 ; 1.42)$ & 0.96 & $(0.74 ; 1.26)$ & \\
\hline \multicolumn{7}{|l|}{ Education } \\
\hline College & 5.4 & 1.00 & - & 1.00 & - & \multirow{4}{*}{$\begin{array}{l}\text { AGE, } \\
\text { GENDER, MST }\end{array}$} \\
\hline High school & 9.3 & 1.80 & $(0.76 ; 4.25)$ & 1.79 & $(0.75 ; 4.29)$ & \\
\hline Elementary school & 14.2 & 2.82 & $(1.22 ; 6.50)^{\mathrm{b}}$ & 2.72 & $(1.17 ; 6.35)^{\mathrm{a}}$ & \\
\hline Illiterate/read & 14.0 & 3.69 & $(1.45 ; 9.43)^{\mathrm{c}}$ & 2.87 & $(1.09 ; 7.57)^{\mathrm{a}}$ & \\
\hline [College-high school] & 8.8 & 1.00 & - & 1.00 & - & \multirow{2}{*}{$\begin{array}{l}\text { AGE, } \\
\text { GENDER, MST }\end{array}$} \\
\hline [Elementary-illiterate] & 14.2 & 1.72 & $(1.29 ; 2.28)^{\mathrm{c}}$ & 1.53 & $(1.21 ; 2.19)^{\mathrm{c}}$ & \\
\hline \multicolumn{7}{|l|}{ Social Class } \\
\hline Upper & 7.7 & 1.00 & - & 1.00 & - & \multirow{4}{*}{$\begin{array}{l}\text { GENDER, } \\
\text { MST }\end{array}$} \\
\hline Middle & 6.3 & 0.81 & $(0.26 ; 2,50)$ & 0.73 & $(0.23 ; 2.30)$ & \\
\hline Working class & 13.5 & 1.87 & $(0.66 ; 5.31)$ & 1.68 & $(0.58 ; 4.85)$ & \\
\hline Poor & 13.3 & 1.83 & $(0.65 ; 5.15)$ & 1.67 & $(0.59 ; 4.79)$ & \\
\hline [Upper-Middle] & 6.6 & 1.00 & - & 1.00 & - & \multirow{2}{*}{$\begin{array}{l}\text { GENDER, } \\
\text { MST }\end{array}$} \\
\hline [Lower-poor] & 13.3 & 2.20 & $(1.40 ; 3.45)^{\mathrm{c}}$ & 2.17 & $(1.36 ; 3.48)^{\mathrm{b}}$ & \\
\hline \multicolumn{7}{|l|}{ Ethnic group } \\
\hline White & 9.4 & 1.00 & - & 1.00 & - & \multirow{5}{*}{$\begin{array}{l}\text { GENDER, } \\
\text { MST, SESDIV }\end{array}$} \\
\hline Moreno & 12.0 & 1.32 & $(0.87 ; 1.98)$ & 1.30 & $(0.85 ; 2.01)$ & \\
\hline Mulatto & 15.7 & 1.79 & $(1.13 ; 2.83)^{\mathrm{b}}$ & 1.78 & $(1.09 ; 2.90)^{\mathrm{a}}$ & \\
\hline Black & 11.2 & 1.22 & $(0.77 ; 1.93)$ & 1.14 & $(0.70 ; 1.87)$ & \\
\hline [Non-white] & 12.7 & 1.40 & $(0.95 ; 2.06)$ & 1.40 & $(0.94 ; 2.09)$ & \\
\hline Total & 12.2 & - & - & - & - & \\
\hline
\end{tabular}

Significance levels: $\mathrm{a}-(0.05>p>0.01) ; \mathrm{b}-(0.01>p>0.005) ; \mathrm{c}-(0.005>p)$.

Table 3 also allows for the analysis of the differential patterns of association between depression and the study independent variables, stratified by gender. In terms of marital status, we collapsed the widowed and divorced subgroups. Among women, there was a nonsignificant gradient in prevalence, from single as compared to married ( $\mathrm{AOR}=1.19)$, and to widowed/ divorced ( $\mathrm{AOR}=1.45$ ). For men, only the married vs. single contrast $(\mathrm{AOR}=2.53)$ reached significance. The small number $(n=37)$ of males divorced or widowed in the sample probably resulted in imprecise estimates. No significant association of migration experience and prevalence of depression was found. For the analysis of the education divide, only for women did we find a significant association $(\mathrm{AOR}=1.82)$, comparing the prevalence of combined college and high school $(11.2 \%)$ to elementary school and illiterate $(19.8 \%)$. 
Table 3

Prevalence (per cent) of depressive disorders according to socioeconomic variables, by gender. Salvador, Brazil, 2001

\begin{tabular}{|c|c|c|c|c|c|c|c|c|c|c|c|}
\hline \multirow[t]{2}{*}{ Variables } & \multirow[t]{2}{*}{ Categories } & \multicolumn{4}{|c|}{ Women } & \multicolumn{4}{|l|}{ Men } & \multicolumn{2}{|c|}{ Female:Male } \\
\hline & & $N$ & Prev\% & $\mathrm{AOR}^{*}$ & (95\% CI.) & $N$ & Prev\% $\%$ & AOR* & $(95 \% \mathrm{CI})$ & $\begin{array}{l}\text { Prevalence } \\
\text { Ratio }\end{array}$ & $\mathrm{MH}-\chi^{2}$ \\
\hline \multirow[t]{3}{*}{ Marital Status } & Single & 273 & 13.6 & 1.00 & - & 291 & 3.4 & 1.00 & - & 4.00 & $18.87^{\mathrm{c}}$ \\
\hline & Married & 768 & 16.7 & 1.19 & $(0.79 ; 1.80)$ & 715 & 8.5 & 2.53 & $(1.27 ; 5.04)^{\mathrm{b}}$ & 1.96 & $22.03^{\mathrm{c}}$ \\
\hline & Widow/divorced & 204 & 20.1 & 1.45 & $(0.83 ; 2.53)$ & 37 & 2.7 & 0.74 & $(0.09 ; 5.94)$ & 9.06 & Exact Test $^{\mathrm{c}}$ \\
\hline \multirow[t]{2}{*}{ Migration } & Non-migrant & 606 & 17.2 & 1.00 & - & 538 & 5.0 & 1.00 & - & 3.44 & $41.44^{\mathrm{c}}$ \\
\hline & Migrant & 643 & 16.0 & 0.92 & $(0.67 ; 1.27)$ & 511 & 9.0 & 1.54 & $(0.92 ; 2.60)$ & 1.55 & $12.47^{\mathrm{c}}$ \\
\hline \multirow[t]{4}{*}{ Education } & College & 62 & 4.8 & 1.00 & - & 49 & 6.1 & 1.00 & - & 0.79 & 0.09 \\
\hline & High School & 392 & 12.2 & 1.74 & $(0.50 ; 6.01)$ & 317 & 5.7 & 0.95 & $(0.27 ; 3.36)$ & 2.14 & $8.95^{\mathrm{b}}$ \\
\hline & Elementary School & 693 & 19.8 & 2.71 & $(0.79 ; 9.29)$ & 642 & 7.5 & 1.25 & $(0.37 ; 4.15)$ & 2.64 & $42.19^{c}$ \\
\hline & Illiterate/Read & 96 & 19.8 & 2.31 & $(0.60 ; 8.90)$ & 36 & 11.1 & 1.83 & $(0.38 ; 8.86)$ & 1.78 & 1.37 \\
\hline \multirow[t]{2}{*}{ Educ. Divide } & [College-High Sch.] & 454 & 11.2 & 1.00 & - & 366 & 5.7 & 1.00 & - & 2.08 & $7.63^{\mathrm{b}}$ \\
\hline & [Elementary-Illiter.] & 789 & 19.8 & 1.82 & $(1.28 ; 2.58)^{\mathrm{c}}$ & 678 & 7.7 & 1.28 & $(0.75 ; 2.20)$ & 2.92 & $43.86^{\mathrm{c}}$ \\
\hline \multirow[t]{4}{*}{ Social Class } & Upper & 28 & 3.6 & 1.00 & - & 24 & 12.5 & 1.00 & - & 0.29 & 1.45 \\
\hline & Middle & 162 & 6.8 & 1.87 & $(0.23 ; 15.19)$ & 122 & 5.7 & 0.40 & $(0.09 ; 1.79)$ & 1.19 & 0.13 \\
\hline & Working class & 350 & 19.1 & 5.29 & $(0.70 ; 40.01)$ & 303 & 6.9 & 0.58 & $(0.15 ; 2.19)$ & 2.77 & $20.77^{\mathrm{c}}$ \\
\hline & Poor & 661 & 18.5 & 5.27 & $(0.70 ; 39.53)$ & 561 & 7.1 & 0.56 & $(0.15 ; 2.07)$ & 2.61 & $33.86^{\mathrm{c}}$ \\
\hline \multirow[t]{2}{*}{ Social Divide } & [Upper-Middle] & 190 & 6.3 & 1.00 & - & 146 & 6.8 & 1.00 & - & 0.93 & 0.04 \\
\hline & [Lower-Poor] & 1011 & 18.7 & 3.02 & $(1.64 ; 5.58)^{\mathrm{C}}$ & 864 & 7.1 & 1.06 & $(0.53 ; 2.13)$ & 2.63 & $54.57^{\mathrm{c}}$ \\
\hline \multirow[t]{4}{*}{ Ethnic Group } & White & 190 & 11.0 & 1.00 & - & 150 & 7.3 & 1.00 & - & 1.51 & 1.36 \\
\hline & Moreno & 560 & 16.4 & 1.41 & $(0.84 ; 2.37)$ & 487 & 7.0 & 1.02 & $(0.49 ; 2.14)$ & 2.34 & $21.96 \mathrm{c}$ \\
\hline & Mulatto & 189 & 19.6 & 1.68 & $(0.92 ; 3.05)$ & 175 & 11.4 & 1.78 & $(0.80 ; 3.96)$ & 1.72 & $4.57^{\mathrm{a}}$ \\
\hline & Black & 261 & 18.4 & 1.54 & $(0.87 ; 2.71)$ & 211 & 2.4 & 0.35 & $(0.12 ; 1.04)$ & 7.67 & $30.04^{\mathrm{a}}$ \\
\hline \multirow[t]{3}{*}{ Ethnic Divide } & [White] & 190 & 11.0 & 1.00 & - & 150 & 7.3 & 1.00 & - & 1.51 & 1.36 \\
\hline & [Non-White] & 1050 & 17.5 & 1.65 & $(1.01 ; 2.69)^{\mathrm{a}}$ & 893 & 6.8 & 1.00 & $(0.50 ; 2.01)$ & 2.59 & $50.79^{\mathrm{c}}$ \\
\hline & Total & 1250 & 16.6 & - & - & 1052 & 6.9 & - & - & 2.41 & $49.49^{c}$ \\
\hline
\end{tabular}


Regarding social class, the prevalence of depression was three times greater among working class, poor women $(18.7 \%)$ as compared to upper/middle-class women $(6.3 \%)$. Among men, no significant differences were found for depression rates across the different social class levels, despite the unexpected highest prevalence $(12.5 \%)$ in the upper stratum. A similar pattern was found for the race/ethnicity analysis. Among women, non-White subgroups showed consistently higher prevalence of depression than Whites. Overall, non-White females were 1.65 times more likely to be depressed than white women. For men, there was no consistent pattern or gradient. Black males showed the lowest prevalence of all strata compared to white males $(\mathrm{AOR}=0.35)$. In sum, the White vs. non-White $\mathrm{racial} / \mathrm{ethnic}$ divide was found in women but not in men $(\mathrm{AOR}=1.00)$.

Table 4 summarizes the stratified analysis of the interactions between gender, social class and ethnicity on the prevalence of depressive disorders. Two-way analysis of gender and social divide (collapsed social classes) revealed again a highly significant effect of gender only among the poor $(\mathrm{MHOR}=3.03)$. The equivalent analysis for gender and ethnicity showed that only White women were not more prone to depression than men. The three-way analysis, including gender, social class, and race/ethnicity, revealed a strong, consistent interaction pattern: none of the racial/ethnic subgroups among the upper-middle class yielded a

Table 4

Prevalence (per cent) of Depressive Disorders and Weighted Mantel-Haezel Odds Ratios (and Confidence Intervals) by Gender, stratified by Social Class and Ethnicity

\begin{tabular}{|c|c|c|c|}
\hline \multirow[t]{3}{*}{ Strata } & \multicolumn{2}{|l|}{ Gender } & \multirow[t]{3}{*}{$\operatorname{MHOR}(95 \% \mathrm{CI})$} \\
\hline & Women & Men & \\
\hline & Prev \% $[N]$ & $\begin{array}{l}\text { Prev \% } \\
{[N]}\end{array}$ & \\
\hline \multicolumn{4}{|c|}{ Upper-Middle } \\
\hline White & $5.1[59]$ & $6.8[44]$ & $0.73(0.09 ; 5.77)$ \\
\hline Moreno & $8.5[71]$ & $1.8[55]$ & $4.98(0.57 ; 23.44)$ \\
\hline Mulatto & 8.7 [23] & $21.7[23]$ & $0.34(0.03 ; 2.47)$ \\
\hline Black & $-[27]$ & {$[22]$} & -- \\
\hline \multirow{2}{*}{\multicolumn{4}{|c|}{$\begin{array}{l}\text { Working class- } \\
\text { Poor }\end{array}$}} \\
\hline & & & \\
\hline White & $14.1[128]$ & 6.9 [102] & $2.22(0.83 ; 6.15)$ \\
\hline Moreno & $18.0[466]$ & $7.9[403]$ & $2.55(1.62 ; 4.02)^{b}$ \\
\hline Mulatto & $20.9[153]$ & 10.1 [149] & $2.36(1.17 ; 4.83)^{\mathrm{a}}$ \\
\hline Black & $20.8[226]$ & $2.7[183]$ & $9.35(3.60 ; 30.69)^{\mathrm{c}}$ \\
\hline
\end{tabular}

Salvador, Bahia, Brazil.

Significance levels: $\mathrm{a}-(0.05>p>0.01)$; $\mathrm{b}-(0.01>p>0.005)$; $\mathrm{c}-(0.005>p)$. significant gender effect. On the other hand, in all racial/ethnic subgroups (except Whites of poor and working-class origin) we found higher prevalence among women. The strong relationship of gender and depression found among Blacks of poor and working-class origins is noteworthy ( $\mathrm{MHOR}=9.35)$.

As shown in Table 5, the White vs. non-White contrast consistently produced non-significant effects across all strata of gender and social classes. The same pattern was observed comparing White-Moreno with Mulatto-Black. However, an interesting interaction between race/ethnicity and gender by social class was observed: no social class effect for males, but a strong, significant effect for women, with poor/working class women at higher risk compared with upper/middle class women among both Whites and non-Whites. The odds ratios were stable and significant for all combinations of female gender and racial/ethnic group, from $\mathrm{OR}=2.7$ to 3.4 , and increasing to $\mathrm{OR}=6.6$ for Mulatto-Black women.

Table 5

Prevalence (per cent) of depressive disorders and weighted mantel-haezel odds ratios (and confidence intervals) by social divide, stratified by gender and ethnic divides

\begin{tabular}{llll}
\hline Strata & $\begin{array}{l}\text { Working } \\
\text { class-Poor }\end{array}$ & $\begin{array}{l}\text { Upper- } \\
\text { Middle }\end{array}$ & MHOR $(95 \% \mathrm{CI})$ \\
\cline { 2 - 3 } & $\begin{array}{l}\text { Prev \% } \\
{[N]}\end{array}$ & Prev \% & \\
& {$[N]$} & \\
\hline
\end{tabular}

\begin{tabular}{|c|c|c|c|}
\hline \multicolumn{4}{|l|}{ Ethnic divide I } \\
\hline White & $6.9[102]$ & $6.8[44]$ & $1.01(0.22 ; 6.33)$ \\
\hline Non-White & $7.1[735]$ & $6.0[100]$ & $1.11(0.46 ; 3.24)$ \\
\hline \multicolumn{4}{|l|}{ Women } \\
\hline White & $14.1[128]$ & $5.1[59]$ & $3.22(0.99 ; 17.66)^{\mathrm{a}}$ \\
\hline Non-White & $19.3[845]$ & $6.6[121]$ & $3.38(1.56 ; 7.62)^{\mathrm{b}}$ \\
\hline \multicolumn{4}{|l|}{ ETHNIC } \\
\hline \multicolumn{4}{|l|}{ DIVIDE II } \\
\hline \multicolumn{4}{|l|}{ Men } \\
\hline White- & $7.8[524]$ & $4.0[100]$ & $2.04(0.71 ; 8.01)$ \\
\hline \multicolumn{4}{|l|}{ Moreno } \\
\hline Mulatto- & $6.0[332]$ & $11.1[45]$ & $0.51(0.17 ; 1.85)$ \\
\hline \multicolumn{4}{|l|}{ Black } \\
\hline \multicolumn{4}{|l|}{ Women } \\
\hline White- & $17.5[624]$ & $7.3[138]$ & $2.71(1.33 ; 5.67)^{\mathrm{b}}$ \\
\hline Moreno & & & \\
\hline $\begin{array}{l}\text { Mulatto- } \\
\text { Black }\end{array}$ & 20.8 [379] & $4.0[50]$ & $6.58(1.66 ; 56.90)^{\mathrm{c}}$ \\
\hline
\end{tabular}

Salvador, Bahia, Brazil.

Significance levels: $\mathrm{a}-(0.05>p>0.01) ; \mathrm{b}-(0.01>p>0.005)$; $c-(0.005>p)$. 


\section{Discussion}

In this survey, we estimated a 12-month prevalence of depressive disorders of $12.2 \%$, which steadily increased with age up to 55 years then decreased thereafter. The overall prevalence estimate was higher than previously reported in the United States and Europe, although the age correlation was strikingly similar. The ECA study yielded one-year prevalence of $9.5 \%$ for mood disorder and of $5.8 \%$ for a major depressive episode (Robins \& Regier, 1991). The NCS found that $17 \%$ of respondents had a lifetime history of depression, while more than $10 \%$ reported a major depressive episode in the past 12 months (Kessler et al., 1994). However, a recent update of both studies (Narrow, Rae, Robins, \& Regier, 2002) presented one-year prevalence estimates of depressive episodes revised for clinical significance: ECA 4.5\%; NCS $6.4 \%$. The British National Survey of Psychiatric Morbidity found an overall prevalence for ICD-10 depressive disorder of $8 \%$ (Jenkins et al., 1997). Other European surveys such as Lindeman et al. (2000), in Finland, Kringlen, Torgersen, and Cramer (2001) in Norway, and de Graaf, Bijl, Smit, Vollebergh, and Spijker (2002), in Holland, consistently reported 12month prevalence of major depressive episode or mood disorders at $8-9 \%$.

Our prevalence estimates were also higher than data from other equivalent morbidity studies conducted elsewhere in Brazil. They were up to $10 \%$ for DSM-III depressive disorders in the Multicentric Study of Psychiatric Morbidity (Almeida-Filho et al., 1997), 8\% for DSM-III-R depressive episode in the São Paulo ECA study (Andrade et al., 2002) and 10\% for CIDI/ ICD-10 diagnosis of depression in the Bambuí study (Vorcaro et al., 2001). It should be noted, however, that each of these studies used a different diagnostic system. For varied reasons, these populations were not fully comparable to the Salvador population, particularly in terms of demographic, ethnic and socioeconomic composition.

Before interpreting our findings, some discussion of methodological aspects is in order, particularly those related to the issues of validity and reliability of the outcome variable as they are linked to diagnostic classification systems. Our study used a self-report case-finding instrument rather than a standardized clinical interview. Prevalence estimates are generally larger in studies that employ this instrument due to the inclusion of individuals with mild or transient psychological disturbance (Blazer, Kessler, McGonagle, \& Swartz, 1994; Regier et al., 1998).

Nonetheless, our primary goal was not to produce accurate occurrence measures of a clinical syndrome but rather to explore the interactions between social determinants of depressive disorders. Given our aims, self-reported data utilizing depression-related QMPA items seemed quite appropriate. Although justified by our immediate research objectives, by doing this, we probably paid the price of inflating the overall prevalence estimates.

Gender was the single most important predictor of depression, with an estimated risk two times greater among females. Controlling for confounders did not reduce the female excess risk. However, there was also variation of the $\mathrm{F}: \mathrm{M}$ ratio according to other dimensions. There was no F:M difference in depression among Whites, the upper and middle classes, the collegeeducated, or the illiterate. On the other hand, prevalence ratios for the single, the widowed and Blacks were well above the overall two-fold gender difference. The Brazilian surveys that used comparable methodology and diagnostic systems also reported F:M ratios of around 2:1 for depression. In Europe and in the USA, $\mathrm{F}: \mathrm{M}$ ratios tend to be lower; namely $1.5: 1$ for a diagnosed depressive episode in Great Britain (Bebbington, Jenkins, Lewis, Brugha, Farrell, \& Meltzer, 1998), Finland (Lindeman et al., 2000) and Holland (de Graaf, et al., 2002). NCS data revealed that women were approximately 1.7 times as likely as men to report both a lifetime history of major depression and major depressive episodes in the past 12 months (Kessler et al., 1994). The Florida Study (Turner \& Gil, 2002) yielded rates of affective and anxiety disorders in females double that of males.

In our data, migratory experience had no effect, either taken alone or in association with other variables. The first wave of studies conducted in Brazil reported a consistent, significant effect of migration upon major depression (Almeida-Filho and Bastos, 1982), neurotic and psychosomatic disorders (Santana, 1982) and poor mental health (Almeida-Filho, 1982). However, later studies found no support for this association (AlmeidaFilho, Mari, \& Coutinho, 1995; Coutinho, AlmeidaFilho, Mari, \& Rodrigues, 1996; Lima et al., 1998). Recently, Almeida-Filho (1998) suggested that internal migration had lost its contextual pathogenic character, given the means of communication-transportation currently available in Brazil.

In our sample, being single was protective for depressive symptoms but stratified analysis showed that only for men was there a significant negative effect of marriage on depression. This result is inconsistent with what has been reported in the US and European literature, where one of the most common findings is a lower risk of mental problems among married as compared to singles (Bebbington, 1998; Kawachi \& Berkman, 2001). Gender has been regarded as an effectmodifier of the association between marital status and minor psychiatric disorders, mainly depression. Whereas married males suffer from these disorders less frequently than singles, among women the opposite has been found (Bebbington et al., 1998). In Western cultural contexts, 
marriage seems to have a protective role for men, but is often detrimental for women (Michael, Berkman, Colditz, \& Kawachi, 2001). In our study we found just the opposite. Nevertheless, as it replicates results from the Brazilian Multicentric Study (Coutinho, Mari, \& Almeida-Filho, 1999), this finding deserves further study, particularly taking into account comorbidity of depression with anxiety and alcoholism.

We found a negative correlation with education: the higher the education level, the lower the prevalence of depression. This gradient was stronger for women than men. Our results are in line with several studies conducted in Brazil (Coutinho, 1976; Lima et al., 1998; Ludermir \& Lewis, 2001; Santana, 1982). Our results also pointed to a social class divide (although not a gradient), with upper and middle classes having lower prevalence as compared to working class and poor. Stratified analyses again confirmed this effect only for women but not for men. There is ample evidence in the literature of an association between SES and the occurrence of depression (Kessler et al., 1994; Gilman, Kawachi, Fitzmaurice, \& Buka, 2002; [77]Yen \& Kaplan, 1999). From an alternative perspective, Wohlfarth (1997) and Belek (2000), respectively, in Israel and in Turkey, independently reported that social class is related to depression and mental health problems independently of correlations between SES and these disorders. Our results lend some support to this hypothesis and suggest that such an independent effect of social class on mental health may occur in interaction with gender.

In the Bahian context, race/ethnicity was not a direct correlate of depressive disorders although higher prevalences of depression were concentrated in the Moreno and Mulatto subgroups. Also, there was no overall racial/ethnic divide between White and non-White, though for females only, we found a significant excess of prevalence for racially mixed groups and the Blacks, when combined. Rickert, Wiemann, and Berenson (2000), studying women seeking reproductive health care, found that $21 \%$ of Whites, $28 \%$ of Blacks, and $29 \%$ of Hispanics reported moderate to severe depressive symptoms (Rickert, Weimann, \& Berenson, 2000). However, studies conducted with different population groups have reported a more diverse picture. A recent survey conducted in South Florida (Turner \& Gil, 2002) replicated results from the NCS in that African Americans had significantly lower rates of affective disorders and overall lifetime comorbidity than nonHispanic white participants (Kessler et al., 1994).

Three-way interaction analyses pointed to a consistent, strong gender effect for the poor and working-class groups, throughout all sub-strata of race/ethnicity but Whites. The stratum Black poor yielded the strongest gender effect of all (up to nine-fold), mostly due to the smallest prevalence found for males. Despite the relatively small number in the subgroup of upper-middle class Black males (49 subjects), the absence of cases of depression among them was striking. As for the combined upper-middle class racial/ethnic groups, Mulatto males had the highest prevalence while Moreno men showed the lowest prevalence. As a result, in this social class stratum, only for Morenos was a strong, significant gender effect (five-fold) found. Finally, there was a consistent social class effect, strongly interacting with gender, throughout all race/ethnicity strata. In the substratum of mulatto-black females, a strong, significant social class effect (seven-fold) was observed.

Before advancing to explain our findings relative to the interaction hypotheses, we should consider first the issue of validity of the data collection process for the assessment of interaction variables. There is room for considering gender bias in our results, given that women exclusively composed the field team. This may have triggered interviewer bias. Female respondents might have been more at ease in talking about symptoms and worries than male respondents. However, available evidence suggests that gender-specific response patterns on self-report scales of psychological symptoms do not explain differences in rates of depression by gender (Stommel et al., 1993; Tousignant, Brousseau, \& Tremblay, 1987). Although methodological issues may to some extent explain a female preponderance in our sample, gender differences in depression appear to be genuine. Furthermore, if we consider gender together with social class and race/ethnicity, it is much less probable that our results were artifactual. In all cases, the increased estimates were due to the lower prevalence reported for three special subgroups: (i) upper-middle class Moreno men; (ii) poor and working-class Black men; (iii) upper-middle class Mulatto and Black women. To suppose that such reduced rates were related to measurement bias is unlikely because these "protected" substrata were composed of different combinations of all gender, social class and race/ethnicity categories.

The gender, race/ethnicity and social class interaction could represent a by-product of comorbidity of depression with related diagnoses (such as anxiety) or competing morbidity with other conditions (e.g. alcohol abuse disorders), as indicated by the NCS (Kessler et al., 1996). This possibility suggests an integrative social causation hypothesis that could explain the gender differential for depression. Proximal pathways for psychosocial illnesses could have anxiety disorders as a previous stage for depression in women, as well as for externalizing disorders, such as substance abuse and dependence, among men (Kendler, Kessler, Neale, Heath, \& Eaves, 1993). Assuming that the abovementioned disorders share genetic and environmental factors, the concept of 'depression spectrum disease' has been suggested to explain the excess of depression in females and alcoholism in males (Cadoret et al., 1996). 
Elsewhere (Almeida-Filho, Lessa, Magalhaes Araújo, Aguino, Kawachi, \& James, 2004), we report a somewhat complementary interaction pattern for gender, ethnicity and social class on alcohol dependence/ abuse.

The available evidence, mainly from Western developed countries, points to several hypotheses to explain why gender is such a consistent risk-factor for depression. There is now a consensus that biological factors have a limited role in the emergence of gender differences in depression (Wilhelm, Parker, \& HadziPavlovic, 1997). Gilman et al. (2002) reported that poor socioeconomic conditions in childhood are an important risk factor for major depression in adult life, and that women were more vulnerable to this particular pathogenic pathway. Stressful life events have been considered an important cause of depressive episodes (Brown \& Harris, 1978). However, the assumption that females are at higher risk of depression from being exposed to adverse life events has received inconsistent support (Bebbington, 1996). At present, there is insufficient evidence for the supposition that women (as opposed to men) are more likely to have "depression-prone" personality characteristics or that women are at higher risk for depression because they have less access to social support than men (Piccineli \& Wilkinson, 2000).

Research on the topic has reported that social support is equally important in males and females as a predictor of recovery from depression, while others have shown greater beneficial effects or even a detrimental action in either of the two genders (Bebbington, 1996; Michael, Berkman, Colditz, \& Kawachi, 2001). On the other hand, epidemiological findings suggest that marriage may have detrimental effects in females, supposedly due to the limited number of roles available to females. Although employment tends to have beneficial effects on psychological well-being, these effects may be reduced or reversed where there is economic discrimination against women, with role overload and role conflict caused by concurrent primary responsibility for household chores and child care (Bebbington, 1996).

As discussed by Piccineli and Wilkinson (2000), the female preponderance to depression is not ubiquitous and varies across different countries as well as across social and cultural groups. This indicates indirectly that social factors and cultural influences contribute to higher depression rates among females. Strong evidence in this regard is provided by studies that have found no gender differences in depression in cultural groups where high value is attached to the female role, such as orthodox Jews in the London area (Loewenthal et al., 1995). However, not only the overall $\mathrm{F}: \mathrm{M}$ ratio but also the risk factors associated to gender differences vary with social and cultural background. The protective effect of marriage for men, for instance, seems to be much more pronounced in post-industrial societies of
Northern Europe than in neo-Latin cultures such as Spain (Vázquez-Barquero et al., 1987) or in Brazil (as shown in our data).

One final word is due regarding our assumption that inequities of class, gender and race/ethnicity were processes, by definition, not only complex but also context- and culture-sensitive. Although the limited methods we used represent a forced de-historicization of our subject matter, we have to recognize that context is embedded in history. The history of Bahia may help us to understand the health situation of the people of contemporary Salvador. If Brazil is known as the "land of contrasts" (Ribeiro, 1995) - which is but a euphemism to designate the prevailing social inequality in the country (Barros, Henriques, \& Mendonca, 2000)Bahia is even more so. Among all Brazilian states, Bahia may be considered as the most heterogeneous on every measure, economically, socially, culturally, and religiously. The first native Brazilian poet, Gregório de Mattos (1636-1695), born in Salvador, wrote this verse: "Triste Bahia, oh quão dessemelhante!" ["Sad Bahia, O so dissimilar!']. It reminds us that, since colonial times, Bahia has suffered from sadness and disparities, or in current technical parlance, depression and inequity.

\section{Acknowledgements}

The data collection for this study was sponsored by the National Center of Epidemiology at the National Health Foundation (Ministry of Health of Brazil). Data analysis was supported by a Pan-American Health Organization/Harvard Center for Society and Health Award for Research on Health Inequalities. CNPq (Brazilian National Reseach Council) and CAPES (Commission for Advanced Training of University Personnel) granted Senior Research Fellowships for N.A.F. and I.L. in different moments of the fieldwork, data analysis and manuscript writing.

\section{References}

Almeida-Filho, N. (1982). The psychosocial costs of development: Labor, migration and stress in Bahia, Brazil. Latin American Research Review, 17, 407-432.

Almeida-Filho, N. (1987). Social epidemiology of mental disorders: A review of Latin American studies. Acta Psychiatrica Scandinavica, 75, 1-10.

Almeida-Filho, N. (1998). Becoming modern after all these years: Social change and mental health in Latin America. Culture, Medicine and Psychiatry, 22(3), 285-316.

Almeida-Filho, N., \& Bastos, S. B. (1982). Estudo casocontrole da associação entre migração e desordens depressivas em mulheres. Jornal Brasileiro de Psiquiatria, 31(1), $25-30$.

Almeida-Filho, N., Lessa, I., Magalhães, L., Araújo, M. J., Aquino, E., Kawachi, I., \& James, S. A. (2004). Alcohol 
drinking patterns by ethnicity, social class, and gender in Salvador, Bahia, Brazil. Revista de Saúde Pública, 38(1), 45-53.

Almeida-Filho, N., Mari, J. J., \& Coutinho, E. (1995). Ruralurban migration and mental health in Latin America: The debate continues. In T. Harpham, \& I. Blue (Eds.), Urbanization and Mental Health in Developing Countries (pp. 41-60). Brookfield: Avebury.

Almeida-Filho, N., Mari, J. J., Coutinho, E., Andreoli, S., Fernandes, J., \& França, J. (1997). Brazilian multicentric study of psychiatric morbidity: Methodological features and prevalence estimates. British Journal of Psychiatry, 171, 524-529.

Andrade, L., Walters, E. E., Gentil, V., \& Laurenti, R. (2002). Prevalence of ICD-10 mental disorders in a catchment area in the city of São Paulo, Brazil. Social Psychiatry and Psychiatric Epidemiology, 37(7), 316-325.

Andreoli, S. B., Mari, J. J., Blay, S. L., Almeida-Filho, N., Coutinho, E., Fernandes, J., \& França, J. F. (1994). Estrutura Fatorial do Questionário de Morbidade Psiquiátrica de Adultos Aplicado em Amostras Populacionais de Cidades Brasileiras. Revista de Saúde Pública, 28(3), 249-260.

Ayuso-Mateos, J. L., Vázquez-Barquero, J. L., Dowrick, C., Lehtinen, V., Dalgard, O., Casey, P., Wilkinson, C., Lasa, L., Page, H., Dunn, G., Wilkinson, G., \& the ODIN GROUP. (2001). Depressive disorders in Europe: Prevalence figures from the ODIN study. British Journal of Psychiatry, 179, 308-316.

Azevedo, E. E. S., Fortuna, C. M., Silva, K. M., \& Silva, M. C. (1982). Spread and diversity of human populations in Bahia, Brazil. Human Biology, 54(2), 329-341.

Barros, P., Henriques, R., \& Mendonça, R. (2000). Desigualdade e Pobreza no Brazil: Retrato de uma estabilidade inaceitável. Revista Brasileira de Ciências Sociais, 15, 123-142.

Bastide, R. (1978). Candomblé da Bahia: Rito Nagô. São Paulo: Companhia Editora Nacional.

Bebbington, P. E. (1996). The origins of sex differences in depressive disorder: Bridging the gap. International Review of Psychiatry, 8, 295-332.

Bebbington, P. E. (1998). Sex and depression. Psychological Medicine, 28, 1-8.

Bebbington, P. E., Jenkins, R., Lewis, G., Brugha, T., Farrell, M., \& Meltzer, H. (1998). The influence of age and sex on the prevalence of depressive conditions: Report from the national survey of psychiatric morbidity. Psychological Medicine, 28, 9-19.

Belek, I. (2000). Social class, income, education, area of residence and psychological distress: Does social class have an independent effect on psychological distress in Antalya, Turkey? Social Psychiatry and Psychiatric Epidemiology, 35, 94-101.

Bhopal, R. (1997). Is research into ethnicity and health racist, unsound, or important science? British Medical Journal, 314,1751 .

Blazer, D., Kessler, R. C., Mcgonagle, K. A., \& Swartz, M. S. (1994). The prevalence and distribution of major depression in a national community sample - the National Comorbidity Survey. American Journal of Psychiatry, 151(7), 979-986.
BMJ. (1996). Editorial: Describing race, ethnicity, and culture in medical research. British Medical Journal, 312, 1054.

Borges, A., \& Filgueiras, L. (1995). Mercado de Trabalho nos Anos 90: O caso da rms. Bahia Análise and Dados, 5(3), 30-36.

Brown, G. W., \& Harris, T. (1978). The social origins of depression: A study of psychiatric disorders in women. London: Tavistock.

Cadoret, R. J., Winokur, G., Langbehn, D., Troughton, E., Yates, W. R., \& Stewart, M. A. (1996). Depression spectrum disease, I: The role of gene-environment interaction. American Journal of Psychiatry, 153, 892-899.

Coutinho, D. M. (1976). Prevalência de doenças mentais em uma comunidade marginal: Um estudo do Maciel. Master's Thesis, Federal University of Bahia, Brazil.

Coutinho, E., Almeida-Filho, N., Mari, J. J., \& Rodrigues, L. (1996). Minor psychiatric morbidity and internal migration in Brazil. Social Psychiatry and Psychiatric Epidemiology, 31, 173-179.

Coutinho, E., Mari, J. J., \& Almeida-Filho, N. (1999). Fatores de risco para morbidade psiquiátrica menor. Revista de Psiquiatria Clínica, 26, 246-256.

De Graaf, R., Bijl, R. V., Smit, F., Vollebergh, W. A. M., \& Spijker, J. (2002). Risk factors for 12-month comorbidity of mood, anxiety, and substance use disorders: Findings from the Netherlands mental health survey and incidence study. American Journal of Psychiatry, 159(4), 620-629.

Fuchs, S. C., Guimarães, S. M., Sortica, C., Wainberg, F., Dias K, . O., Ughini, M., Castro, J. A. S., \& Fuchs, F. D. (2002). Reliability of race assessment based on the race of the ascendants: A cross-sectional study. BMC Public Health, 2(1), 1-10 (Epub Jan 16, 2002).

Gilman, S. E., Kawachi, I., Fitzmaurice, G. M., \& Buka, S. L. (2002). Socioeconomic status in childhood and the lifetime risk of major depression. International Journal of Epidemiology, 31(2), 359-367.

Griffin J, M., Fuhrer, R., Stansfeld, S., \& Marmot, M. (2002). The importance of low control at work and home on depression and anxiety: Do these effects vary by gender and social class? Social Science \& Medicine, 54, 783-798.

Jenkins, R., Bebbington, P., Brugha, T., Farrell, M., Gill, B., Lewis, G., Meltzer, H., \& Petticrew, M. (1997). The National Psychiatric Morbidity Surveys of Great Britainstrategy and methods. Psychological Medicine, 27, 765-774.

Kawachi, I., \& Berkman, L. (2001). Social ties and mental health. Journal of Urban Health, 78, 458-467.

Kendler, K. S., Kessler, R. C., Neale, M. C., Heath, A. C., \& Eaves, L. J. (1993). The prediction of major depression in women: Toward an integrated etiologic model. American Journal of Psychiatry, 150, 1139-1148.

Kessler, R. C., McGonagle, K. A., Zhao, S., Nelson, C. B., Hughes, M., Eshleman, S., Wittchen, H. U., \& Kendler, K. S. (1994). Lifetime and 12-month prevalence of DSM-III-R psychiatric disorders in the United States. Results from the National Comorbidity Survey. Archives of General Psychiatry, 51, 8-19.

Kessler, R. C., Nelson, C. B., McGonagle, K. A., Liu, J., Swartz, M., \& Blazer, D. G. (1996). Comorbidity of DSMIII-R major depressive disorder in the general population: Results from the US National Comorbidity Survey. British Journal of Psychiatry, 168(suppl. 30), 17-30. 
Kraay, H., \& Levine, R. M. (1998). Afro-Brazilian culture and politics: Bahia, 1790s to 1990s. Durham: Duke University Press.

Krieger, N. (2000). Refiguring race: Epidemiology, racialized biology, and biological expressions of race relations. International Journal of Health Services, 30, 211-216.

Krieger, N., Rowley, D. L., Herman, A. A., Avery, B., \& Phillips, M. T. (1993). Racism, sexism, and social class: Implications for studies of health, disease, and well-being. American Journal of Preventive Medicine, 9(suppl. 1), $82-122$.

Krieger, N., Williams, D., \& Moss, N. (1997). Measuring social class in US public health research: Concepts, methodologies and guidelines. Annual Review of Public Health, 18, 341-378.

Kringlen, E., Torgersen, S., \& Cramer, V. (2001). A Norwegian psychiatric epidemiological study. American Journal of Psychiatry, 158(7), 1091-1098.

Lennon, M. C. (1995). Work conditions as explanations for the relation between socioeconomic status, gender and psychological disorders. Epidemiologic Reviews, 17, 120-127.

Lillie-Blanton, M., \& Laveist, T. (1996). Race/ethnicity, the social environment, and health. Social Science \& Medicine, 43(1), 83-91.

Lima, A. M. V., \& Azevedo, E. S. (1991). Factor-VIII-C, ABO blood groups and black admixture in a Brazilian Sample. Human Biology, 63, 77-83.

Lima, M. S., Soares, B. G., \& Mari, J. J. (1998). Saúde e doença mental em Pelotas, RS: Dados de um estudo populacional. Revista de Psiquiatria Clínica, 25(5), 233-242.

Lin, K. M. (2001). Biological differences in depression and anxiety across races and ethnic groups. Journal of Clinical Psychiatry, 62 (Suppl. 13), 13-9, 20-21.

Lindeman, S., Hamalainen, J., Isometsa, E., Kaprio, J., Poikolainen, K., Heikkinen, M., \& Aro, H. (2000). The 12-month prevalence and risk factors for major depressive episode in Finland: Representative sample of 5993 adults. Acta Psychiatrica Scandinavica, 102(3), 178-184.

Link, B. G., Lennon, M. C., \& Dohrenwend, B. P. (1993). Socioeconomic status and depression: The role of occupations involving direction, control, and planning. American Journal of Sociology, 98, 1351-1387.

Loewenthal, K., Goldblatt, V., Gorton, T., Lubitsch, G., Bicknell, H., Fellowes, D., \& Sowden, A. (1995). Gender and depression in Anglo-Jewry. Psychological Medicine, 25, 1051-1064.

Ludermir, A. B., \& Lewis, G. (2001). Links between social class and common mental disorders in Northeast Brazil. Social Psychiatry and Psychiatric Epidemiology, 36, 101-107.

Maier, W., Gänsicke, M., Gater, R., Rezaki, M., Tiemens, B., \& Florenzano-Urzúa, R. (1999). Gender differences in the prevalence of depression: A survey in primary care. Journal of Affective Disorders, 53, 241-252.

Mari, J., Almeida-Filho, N., Coutinho, E., Andreoli, S., Miranda, C., \& Streiner, D. (1993). The epidemiology of psychotropic use in the city of São Paulo. Psychological Medicine, 23, 467-474.

Michael, Y. L., Berkman, L. F., Colditz, G. A., \& Kawachi I, . (2001). Living arrangements, social integration, and change in functional health status. American Journal of Epidemiology, 153, 123-131.
Muntaner, C., Eaton, W. W., \& Diala, C. C. (2000). Socioeconomic inequalities in mental health: A review of concepts and underlying assumptions. Health, 4, 82-106.

Narrow, W. E., Rae, D. S., Robins, L. N., \& Regier, D. A. (2002). Revised prevalence estimates of mental disorders in the United States: Using a clinical significance criterion to reconcile 2 surveys' estimates. Archives of General Psychiatry, 59(2), 115-123.

Nobles, M. (2000). History counts: A comparative analysis of racial/color categorization in US and Brazilian censuses. American Journal of Public Health, 90(11), $1738-1745$.

Piccinelli, M., \& Wilkinson, F. (2000). Gender differences in depression: Critical review. British Journal of Psychiatry, 177, 486-492.

Queiroz L, . (1995). O Turismo Baiano na Competitividade Internacional. Bahia Análise \& Dados, 5(3), 105-113.

Regier, D. A., Kaelber, C. T., Rae, D. S., Farmer, M. E., Knauper, B., Kessler, R. C., \& Norquist, G. S. (1998). Limitations of diagnostic criteria and assessment instruments for mental disorders. Archives of General Psychiatry, $55,109-115$.

Rego, V. (1980). Mitos e Ritos Africanos da Bahia. In Iconografia dos Deuses Africanos no Candomblé da Bahia, Carybé, H. (pp. 3-27). Salvador: Fundação Cultural do Estado da Bahia and UFBA/São Paulo: Instituto Nacional do Livro.

Reichmann, R. (1999). Race in contemporary Brazil: From indifference to inequality. New York: Cambridge University Press.

Ribeiro, D. (1995). O povo brasileiro: A formação e o Sentido do Brasil. São Paulo: Editora Companhia das Letras.

Rickert, V. I., Wiemann, C. M., \& Berenson, A. B. (2000). Ethnic differences in depressive symptomatology among young women. Obstetrics and Gynecology, 95, 55-60 (January 1).

Risério, A. (2000). Uma história da cidade da Bahia. Salvador, Bahia: Omar G. Editora.

Ritsher, J. E. B., Warner, V., Johnson, J. G., \& Dohrenwend, B. P. (2001). Inter-generational longitudinal study of social class and depression: A test of social causation and social selection models. British Journal of Psychiatry, 178(Suppl. 1), S84-S90.

Robins, L., Regier, D. (Eds.) (1991). Psychiatric disorders in America. New York: The Free Press.

Santana, V. (1982). Estudo epidemiológico das doenças mentais em um bairro de Salvador. Série de Estudos em Saude, 3, $1-122$.

Souza, G. A., \& Faria V, . (1980). Bahia de Todos os Pobres. Petrópolis: Vozes.

Stommel, M., Given, G. A., Given, C. W., Kalaian, H. A., Schulz, R., \& McCorkle, R. (1993). Gender bias in the measurement properties of the Centre for Epidemiologic Studies Depression Scale (CES-D). Psychiatry Research, 49, 239-250.

Tousignant, M., Brosseau, R., \& Tremblay, L. (1987). Sex biases in mental health scales: Do women tend to report less serious symptoms and confide more than men? Psychological Medicine, 17, 203-215.

Turner, J., \& Gil, A. G. (2002). Psychiatric and substance use disorders in South Florida: Racial/ethnic and gender 
contrasts in a young adult cohort. Archives of General Psychiatry, 59, 43-50.

Vázquez-Barquero, J. L., Diez-Manrique, J. F., Pena, C., Aldama, J., Samaniego-Rodriguez, C., Menendez-Arango, J., \& Mirapeix, C. (1987). A community mental health survey in Cantabria: A general description of morbidity. Psychological Medicine, 17, 227-242.

Vorcaro, C. M., Lima-Costa, M. F., Barreto, S., \& Uchoa, E. (2001). Unexpected high prevalence of 1-month depression in a small Brazilian community: The Bambui study. Acta Psychiatrica Scandinavica, 104(4), 257-263.

Weissman, M. M., \& Klerman, G. L. (1977). Sex differences and the epidemiology of depression. Archives of General Psychiatry, 34, 98-111.
Wilhelm, K., Parker, G., \& Hadzi-Pavlovic, D. (1997). Fifteen years on: Evolving ideas in researching sex differences in depression. Psychological Medicine, 27, 875-883.

Williams, D., Takeuchi, D., \& Adair, R. (1992). Socioeconomic-status and psychiatric-disorder among Blacks and Whites. Social Forces, 71(1), 179-194.

Wohlfarth, T. (1997). Socioeconomic Inequality and Psychopathology: Are socioeconomic status and social class interchangeable? Social Science \& Medicine, 45, 399-410.

Yen, I. H., \& Kaplan, G. (1999). Poverty area residence and changes in depression and perceived health status: Evidence from the Alameda county study. International Journal of Epidemiology, 28, 90-94. 